\title{
ASPECTOS DE LA PLURALIZACIÓN RELIGIOSA A PARTIR DEL INGRESO DE LA MISIÓN THE CHRISTIAN AND MISSIONARY ALLIANCE EN EL SUR CHILENO, EL CASO DEL MISIONERO METODISTA ALBERT DAWSON (1897 - 1914)*1
}

\author{
ASPECTS OF RELIGIOUS PLURALIZATION AFTER THE ENTRY OF THE \\ CHRISTIAN AND MISSIONARY ALLIANCE IN SOUTHERN CHILE, THE \\ CASE OF THE METHODIST MISSIONARY ALBERT DAWSON (1897 - 1914)
}

\author{
Darío Escobar Sepúlveda ${ }^{2}$ \\ dario.escobar@ulagos.cl \\ Universidad de Los Lagos \\ Osorno, Chile \\ DOI: https://doi.org/10.32735/S2735-61752020000117147
}

\section{RESUMEN}

El ingreso de diversos cultos protestantes a Chile desde mediados del siglo XIX tensionó el orden religioso establecido dando un impulso y transformando las esferas de discusión acerca del lugar que debía tener la religión en la construcción del Estado chileno. En este contexto de tensiones político religiosas que se vincularon al proceso de secularización de la sociedad chilena, ingresó a fines del siglo XIX la Misión The Christian and Missionary Alliance, una organización estadounidense que buscaba instalarse en el territorio del sur chileno en búsqueda de nuevos prosélitos. Este artículo da cuenta del proceso de establecimiento de la Misión The Christian and Missionary Alliance, en la persona de uno de sus fundadores, Albert E. Dawson, un ministro religioso metodista canadiense que arribó a Chile durante 1897 e hizo una cruzada apostólica hasta el año 1914; la instalación de esta Misión en Chile se vinculó en buena parte a las actividades de este misionero el cual ha sido silenciado tanto de la historiografía chilena como de la memoria del evangelicalismo chileno.

Palabras claves: Misión The Christian and Missionary Alliance; Albert Dawson; secularización; evangelización.

\footnotetext{
ABSTRACT

The entry of various Protestant cults into Chile since the mid-nineteenth century stressed the established religious order, giving a boost and transforming the spheres of discussion about the place that religion should have in the construction of the Chilean State. In this context of politicalreligious tensions that were linked to the process of secularization of Chilean society, at the end of the 19th century the Mission The Christian and Missionary Alliance, an American organization that sought to settle in the southern Chilean territory in search of new proselytes, joined. . This article gives an account of the process of establishing the Mission The Christian and Missionary Alliance, in the person of one of its founders, Albert E. Dawson, a Canadian Methodist religious minister who arrived in Chile during 1897 and made an apostolic crusade until the year 1914;

* Artículo recibido el 7 de marzo de 2018; aceptado el 01 de junio de 2018.

1 El presente artículo es resultado del proyecto PIP 11220150100838 , "Biopolítica de la territorialización norpatagónica en el siglo XX", financiado por el Consejo Nacional de Investigaciones Científicas y Técnicas (CONICET-Argentina).

${ }^{2}$ Magíster en Ciencias Humanas mención Historia, por la Universidad de Los Lagos.
} 
The installation of this Mission in Chile was largely linked to the activities of this missionary, who has been silenced both from Chilean historiography and from the memory of Chilean evangelicalism.

Key words: Mision The Christian and Missionary Alliance; Albert Dawson; secularization; evangelization.

\section{Introducción}

Durante la segunda mitad del siglo XIX el sur chileno se convirtió en un territorio tensionado por el ingreso y avance de distintas corrientes religiosas protestantes vinculadas a iglesias históricas y de organizaciones misioneras provenientes, principalmente, desde Estados Unidos y Europa.

El establecimiento y desarrollo de estas iniciativas religiosas no católicas en el territorio nacional contribuyó al proceso de secularización del Estado chileno (Becerra, 2013; Millar, 2000; Serrano, 2003). En este escenario de tensiones se cita el ingreso de la Misión The Christian and Missionary Alliance (en adelante: la Misión The Alliance) durante el año 1897, con tres misioneros norteamericanos. Uno de ellos fue Albert Dawson, un profesor y misionero metodista canadiense que se encontraba trabajando entre las tribus indígenas en su país (según el anual report of the Department of Indian Affairs de Canadá, del año 1897), el cual solicitó su ingreso a la The Alliance en Estados Unidos para aventurarse a trabajar en Chile.

La estrategia de esta Misión protestante se puede vincular a una visión escatológica del fin de los tiempos, de modo que las acciones apostólicas mundiales debían realizarse en el menor tiempo y el mayor alcance posible (Woerner, 1997). En este escenario de urgencia la Misión The Alliance puso sus esfuerzos en América del Sur luego que el misionero sueco Emilio Olssen convenciera al fundador de la Misión en Nueva York, el presbiteriano Albert Benjamín Simpson, que este continente podía ser evangelizado en un plazo de cuatro años. Su idea se relacionó fundamentalmente en la experiencia del mismo Olssen por sus variados viajes de vendedor de literatura religiosa y evangelista prominente desde Buenos Aires, Bolivia y Valdivia en Chile (Shanonn, 1997). En consecuencia, los tres misioneros destinados a Chile arribaron al puerto de Talcahuano (Chile) el 19 de Abril de 1897, estos fueron Albert Dawson y el matrimonio menonita de Henry Weiss y Katherine Zacharias.

El ingreso de los misioneros de la Misión The Alliance no se vincula a políticas gubernamentales de migración, como fue el caso de los migrantes europeos que ingresaron al país y que, en su mayoría, fueron vinculados al luteranismo. El objetivo principal de estos misioneros era la evangelización de la población nacional mediante el mensaje del evangelio, el cual pretendía la conversión de la persona humana entendida como una experiencia esencial para la salvación (Ospina, 2015) principio que coincide en buena medida con la doctrina metodista de salvación, la cual fue promovida escasamente por las iglesias del protestantismo histórico que se habían instalado en Chile durante el siglo XIX.

De este modo, el presente artículo busca contribuir a la historiografía religiosa en Chile, mediante la incorporación de documentos que no han sido trabajados previamente y que aportan nuevos y originales antecedentes que pueden fortalecer la comprensión del desarrollo del protestantismo a partir de la persona del misionero Albert Dawson, lo cual nos permitirá identificar y explicar las tensiones surgidas a partir de su propia persona y de la Misión que él representaba mediante la descripción de sus variados viajes y episodios de resistencia religiosa durante 1897 a 1914. Particularmente se podrá identificar la ruta de evangelización y sus 
esfuerzos por sacralizar espacios privados mediante la construcción de capillas y lugares de culto doméstico.

\section{Escenario del protestantismo histórico en Chile previo al ingreso de la Misión The Alliance}

A mediados del siglo XIX el sur chileno experimentó el ingreso de migrantes europeos que modificó la composición poblacional como consecuencia de la estrategia de colonización, desarrollo y modernización del territorio que impulsó el gobierno de Manuel Bulnes mediante la Ley de Colonización promulgada en 1845. Esta política repercutió en distintos escenarios, ejemplo de ello es la problemática de la tenencia de tierras que se encontraban en posesión mayoritariamente de población indígena y que fueron entregadas a los colonos y la modificación de las prácticas productivas, entre otros (Almonacid, 2009; Pinto, 2011; Muñoz, 2008), también en el ingreso de corrientes religiosas de origen protestante asociadas a los mismos inmigrantes, las que modificaron el escenario religioso establecido generando diversas reacciones de descontento de la Iglesia Católica en contra la política de gobierno y en contra de quienes comulguen en estos nuevos cultos, incluso llamó a su feligresía a que no se involucren en los cultos reformados, no lean ni cooperen en propaganda que ataque las doctrinas católicas porque era ilícito y pecado mortal (Muñoz, 2010).

Sin embargo, la hegemonía del discurso católico ya se encontraba tensionado a causa del ingreso de una serie de pioneros con formación ideológica liberal inspirados en ideales libertarios que buscaron aliados que contribuyan al quiebre del dominio religioso, cultural y político de la Iglesia Católica (Salinas, 1987). De estos esfuerzos surgió un frente anticlerical que garantizó la ruptura del régimen colonial y de sus instituciones, incluyendo el discurso hegemónico del que gozaba la iglesia Católica (Castro, 2013; Carvajal, 2009). Sin embargo, parece que las discusiones de qué hacer con la religión frente al establecimiento y desarrollo de un Estado laico era una constante discusión tanto parlamentaria como de los promotores de los principales cultos que se desarrollaban en Chile y, el punto neurálgico aparentemente era la secularización como una ideología de la modernidad que venía buscando su lugar en la sociedad chilena.

La secularización en Chile ha sido un fenómeno dinámico que es necesario matizar, tanto un fenómeno surgido desde la modernidad del cual lo más sencillo ha sido afirmar que buscaba la superación de la superstición y las creencias, dando lugar al desarrollo de la razón humana. Sin embargo, al referirse al caso de la construcción del Estado en Chile (y la mayoría otros países americanos), la secularización no tuvo un comportamiento como tal, sino que se manifestó en un proceso de pluralización religiosa el cual sugería la incorporación de nuevos discursos religiosos y el debilitamiento impostergable de la hegemonía religiosa católica. En efecto, se entenderá por secularización como:

la diferenciación y autonomía de las esferas secular y religiosa en los más diversos ámbitos de la sociedad moderna desde el conocimiento científico, el capitalismo o la urbanización, y no tiene como consecuencia necesaria la declinación de la religión sino su privatización. Este es el punto central desde la perspectiva de la historia política. La historia de la secularización del Estado es fundamental para comprender 
y conceptualizar el papel público de las religiones en las sociedades modernas

(Serrano, 2008, p. 22).

La secularización es uno de los variados y dinámicos resultados que trajo consigo la modernidad. Lo secular se entenderá como un concepto en oposición a lo sagrado y en sus derivaciones sugiere una emancipación cultural con respecto de la religión y de la Iglesia que está asociada a su fe, pero también en concepto sugiere la promoción de una política o de un cierto programa republicano (Dobbelaere, 1994, p. 7).

Según Jorge Larraín, la mirada crítica del pensamiento social moderno y en consecuencia los grandes destellos de la secularización, con respecto a la religión se desarrollaron en una esfera tridireccional, la primera destacaba la necesidad de establecer una nueva metodología para aproximarse a la naturaleza que superara las limitaciones de la teología y, en consecuencia, de la religión. La segunda se situaba en la sospecha de que la idea de Dios estaba relacionada directamente con la legitimación del poder político y la teoría de la secularización progresiva de la sociedad como un proceso que terminaría por desplazar la religión y la tercera era el desplazamiento de la religión (Larraín, 2003, p. 12-13). Esta afirmación permite destacar que las tres direcciones apuntaron al sentido de secularización. Entender la superación de la teología frente a lo natural resulta una poderosa mirada respecto del surgimiento del pensamiento moderno, toda vez que para entender lo natural, el ser humano debía vaciarse de su condición religiosa. Agustín Izquierdo interpretando a Friedrich Nietzsche afirmó la idea de esta separación entre lo natural y sobrenatural desde el mismo ser humano:

Las morales y las religiones son el medio principal para hacer del hombre lo que se quiera: siempre que se posea un exceso de fuerza creativa y se pueda imponer su voluntad en largos periodos de tiempo. Pagano - Cristiano. Pagano es decir sí a lo natural, al sentimiento de inocencia en lo natural, la naturalidad. Cristiano es decir no a lo natural, es el sentimiento de indignidad en lo natural, la antinaturalidad. (Izquierdo, 2003, p. 157). 
Bajo el escenario de desarrollo de la secularización de la sociedad chilena, entendida como la pluralización del discurso religioso, ingresaron a Chile una serie de iglesias del protestantismo histórico. Para ello se presenta el siguiente cuadro resumen extraído del libro "South America. The neglectec continent" de los autores E. C. Millard y Lucy Guinnes (1894):

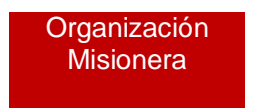

Misión

Presbiteriana

Americana (N. \&

S.)

Misión Obispo

Williams Taylor

Sociedad Bíblica

Americana $^{3}$

Sociedad

Misionera

Sudamericana

Sociedad Bíblica

Británica y

Extranjera $^{4}$

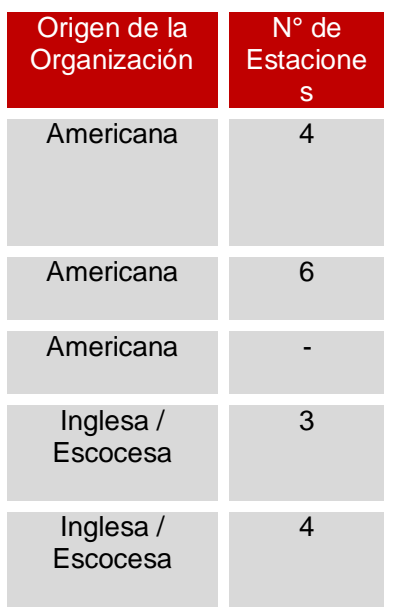

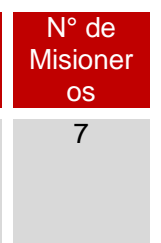

14

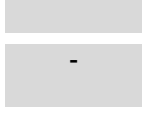

3

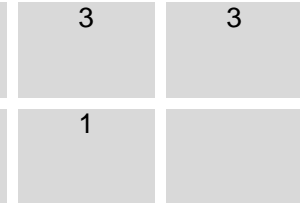

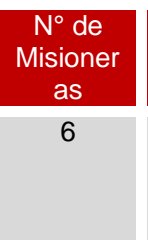

28

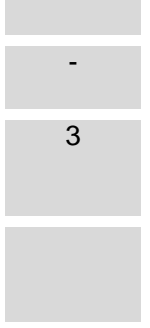

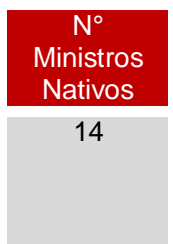

16
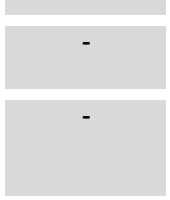

4
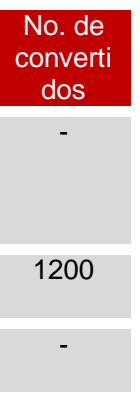

570

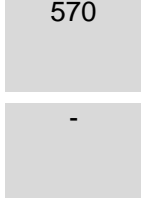

Año de

inicio del

trabajo

1861

1880

1864

1854

1824

Figura 1. Cuadro resumen. Fuente: Millard y Guinnes (1894), 181-182.

El catastro hizo un panorama general de las organizaciones internacionales que buscaron establecerse en Chile para realizar sus acciones misionales de orden protestante. Todas ellas son extranjeras, norteamericanas o británicas. Sin embargo, la incorporación del protestantismo hasta fines del siglo XIX no fue importante. La lectura de los censos reportaron que no existió un importante cambio religioso en ese período. La movilidad religiosa, para el año 1895 era muy leve:

Si tenemos en consideración la movilidad social y religiosa que han desarrollado los chilenos desde 1895, en que se realizó el VII Censo General de Población, es la primera vez en que se consulta sobre el sentido de pertenencia religiosa a las personas. Según el Censo de 1895, vivían en el país 2.712.145 personas; 1.332.385 eran hombres y 1.379 .760 mujeres; de ellos 79.065 eran extranjeros... los católicos representan un $99,40 \%$, protestantes representan un $0,54 \%$, religiones orientales $0,01 \%$, ateos, sin religión, racionalistas son representados por un $0,03 \%$ de la población. (Sánchez, 2017, p. 644).

\footnotetext{
${ }^{3}$ Esta organización no indica datos pero se insertó la frase "grant made to the Valparaíso Bible Society" (donaciones hechas a la Sociedad Bíblica de Valparaíso).

${ }^{4}$ Los autores anotaron la siguiente aclaratoria: "The British and Foreing Bible Society make an annual grant to the Valparaíso Bible Society" (La Sociedad Bíblica Británica y Extranjera hace una gran donación anual a la Sociedad Bíblica de Valparaíso). Además, los autores marcaron a esta organización trabajando en Chile y Perú simultáneamente.
} 
Las primeras iglesias protestantes en Chile tuvieron sus orígenes en las Misiones que se establecieron en el país. Posteriormente, y a causa de las sucesivas olas de inmigrantes, se fueron estableciendo otras iglesias, las que no fueron fruto del trabajo específico de las Misiones descritas por Millard y Guinnes en 1894. Hay que precisar de igual modo, que el año de ingreso de las Misiones protestantes no originó una inmediata adhesión de población nacional, sino que fue un trabajo progresivo. La instalación de capillas o iglesias que albergaran los cultos protestantes fue posterior. El texto inicial de Millard y Guinnes (1894) nos ubica en la amplitud geográfica de misiones poco relevadas, respecto de otros cultos, dentro de Chile.

Por otro lado hay que considerar que las primeras congregaciones protestantes no surgieron por un acuerdo mecánico en el cual un grupo de creyentes dejaba su país de origen para trasladarse a Chile y permanecer en su estado original. Al contrario, atendiendo a las afirmaciones de Alina Silveira (2017), las iglesias protestantes que pretendían instalarse en Chile debieron someterse a un proceso de adaptación a las circunstancias de las:

sociedades de recepción que diferirían ampliamente de las condiciones en los países europeos, lo cual las llevó en muchos casos a convertirse en refugios de etnicidad cuyo objetivo era preservar una identidad nacional inventada y reconstruida entre los inmigrantes; función que no desempeñaron en sus países de origen.

Una de las principales características de las cuales gozaban las congregaciones protestantes en Chile, fue su indiscutido carácter histórico por tanto contenían un dogma establecido y una organización eclesiástica organizada. No fue el caso de la Misión The Alliance, la cual carecía de estas características cuando ingresó a Chile.

\section{Del protestantismo histórico al protestantismo misionero en Chile: el ingreso de la Misión The Alliance en 1897}

Un aspecto que se vuelve relevante rescatar es que para el siglo XIX todas las organizaciones religiosas no católicas establecidas en Chile tuvieron en común su carácter histórico. La historiografía chilena y en general la latinoamericana en el mayor de los casos, no logra dar cuenta de la sutileza que envuelve el término «protestante», sin hacer mayor diferenciación o análisis del origen de cada Misión que se pretendía establecer. Al respecto, este calificativo tiene una interesante connotación para enfrentar la siguiente Misión en estudio porque tiene orígenes diferentes a las organizaciones ya establecidas en Chile.

La revisión que hizo el teórico Fernando García Leguizamón (2012), permitió hacer una diferenciación, no sólo en los términos utilizados sino en el origen de cada Misión. Respecto de los protestantes, afirmó que:

A los disidentes luteranos (seguidores de Lutero) que apoyaban la Reforma se les llamó en adelante 'protestantes' y ellos mismos adoptaron el calificativo, que se amplió además para denominar a las tres doctrinas cristianas no católicas que surgieron el siglo XVI: luterana, calvinista y anglicana...las iglesias fundamentadas en 
las doctrinas de Juan Calvino adoptan predominantemente el término de 'reformada' (García Leguizamón, 2012, p. 173).

A partir de esta aclaración, se puede caracterizar a las Misiones anglicanas y metodistas como protestantes, mientras que la Misión Presbiteriana como reformada.

La instalación de iglesias no católicas en Chile implicó múltiples esfuerzos misioneros de connotación protestante y/o reformado (en el caso presbiteriano); sin embargo, las nuevas Misiones que intentaban establecerse carecieron de una raíz histórica, por lo tanto no es posible categorizarlas del mismo modo. Por lo tanto, la categoría que logra representar a las Misiones que ingresaron al país, luego de las históricas, son aquellas surgidas del "evangelicalismo" que, en resumen fueron aquellas Misiones u organizaciones que:

deploraban el languidecimiento de la fe originaria, lo que veían como consecuencia de la formalización en la que habían caído las nuevas iglesias (las separadas de la iglesia católica), que entablaron una cruzada contra la rutinización y la ritualización mecánica, llamando a un despertar o reavivamiento de la vida piadosa...un primer despertar tuvo lugar en Europa y las colonias norteamericanas, aproximadamente entre 1720 y $1750 \ldots$ el segundo gran despertar se dio en Estados Unidos entre 1795 y 1835 y de allí se extendió a Inglaterra. A partir de entonces aparecieron 'revivalistas' profesionales que viajaban por pueblos y ciudades, organizando encuentros anuales de reavivamiento.... El tercer gran despertar tuvo lugar entre 1875 y 1915 y se dirigió, de una parte, a evangelizar las masas de obreros de las urbes industrializadas, y de otra, a hacer frente a la cada vez más difundida visión materialista de la naturaleza inspirada en la teoría de la evolución. Aunque el adjetivo 'evangélico' había sido utilizado con frecuencia desde el siglo XVI para nombrar a los protestantes en general, hacia finales del siglo XIX el término empieza a designar en los Estados Unidos a un sector particular de protestantes que, además de afirmar su creencia en el Evangelio, de una parte se distancian enfáticamente de la teología liberal desmitologizante que permeaba por entonces a las iglesias protestantes, para defender, por el contrario, una interpretación literal de la Biblia a la que consideraban 
como inspirada plenamente por la Divinidad.... De otra parte, se adhieren a la escatología premilenialista... (García Leguizamón, 2012, p. 174-175).

En este caso, la fundación de la organización religiosa Misión The Alliance se encuentra dentro del marco del tercer gran despertar religioso protestante que tuvo lugar en Estados Unidos y que, en consecuencia, tiene un interesante vínculo con la necesidad de la evangelización de poblaciones subalternas.

Chile fue uno de los tantos objetivos de la Misión The Alliance porque éstos tenían un conocimiento previo acerca del panorama religioso en el cual se encontraba el país, y en general de toda América del Sur, posiblemente a los testimonios publicados por el misionero metodista estadounidense William Taylor. En éstos manifestaba que, en el caso chileno, ya tenían misioneros establecidos en el país pero éstos no podían lograr solos la evangelización de una población de al menos dos millones de personas. Posteriormente, la prensa de la Misión en Estados Unidos publicó reiterados anuncios acerca del poder religioso hegemónico del cual gozaba la Iglesia Católica, los conflictos diplomáticos con Perú y el progresivo avance de la masonería ${ }^{5}$, de esta manera, el envío de misioneros a América del Sur comenzó a ser prioritario.

La dinámica de evangelización de la Misión The Alliance propició los esfuerzos para establecerse en América del Sur porque era considerado un continente descuidado. Los países del sur americano se encontraban en proceso de consolidación y donde el poder e imaginario religioso se concentraba en el catolicismo colonial del cual querían desprenderse; al respecto, los misioneros fueron enviados en varias etapas:

...se hizo una reunión de despedida a la que fuimos [convocados] para que nos informen sobre la salida de otro grupo de misioneros a América del Sur. El principal objetivo del Sr. Emilio Olssen es llevar adelante la apertura de una nueva campaña para la evangelización del continente olvidado. Cinco han tomado la delantera, el el Sr. y la Sra Bailley a Venezuela, el señor y la señora Weiss y el señor Dawson a Chile y ahora otros siete se han ido a otros países. Ellos deben estar localizados de la siguiente manera: el Sr. Clark irá a Panamá en Colombia. El Sr. Fritz a Ecuador en la ciudad de Guayaquil, el Sr. Arnold a Poono, Perú; El Sr. Nebius a Bolivia, el Sr.

\footnotetext{
${ }^{5}$ Estos argumentos surgen de los diversos artículos analizados de la revista de la Misión The Christian and Missionary Alliance en Estados Unidos (En adelante Revista The Alliance): acerca de los testimonios de William Taylor, artículo publicado el 01 de Enero de 1882 (página 41), el cual contiene un panorama general de la población en los países de América del Sur y su necesidad por evangelizarlos; acerca del conflicto diplomático entre Chile y Perú, artículo publicado el 01 de Enero de 1883 (página 16), donde además informó que Venezuela enfrentaba una revolución donde Ecuador se encontraba comprometido, hay amenazas hostiles entre Brasil y Argentina, mientras que México y Guatemala se encontraban en la misma situación; acerca del avance de la masonería, artículo publicado el 26 de Junio de 1896 (página 613) que afirmaba- en el caso de América del Sur - que en Chile y México se encontraba organizada la logia masona.
} 
Thacker a Montevideo y el Sr. Hathaway a Buenos Aires. El Sr. Olssen acompañará esta partida hasta Panamá y de allí seguirá a la costa a través de Caracas y de Brasil a Buenos Aires. El [nuevo equipo] se compone de doce personas [...] nueve ya están en el campo [...] en América del Sur 6 ...

El misionero Albert Dawson se embarcó el 10 de marzo de 1987 desde el puerto de Nueva York con destino a Chile, llegó el 19 de Abril al puerto de Talcahuano, acompañado por Henry Weiss y Katherine Zacharias, un matrimonio menonita que al igual que Dawson, se asoció a la Misión The Alliance, éstos fueron enviados sin sueldo, debiendo trabajar en diversas actividades para sustentarse. En el caso del misionero Dawson, éste se sustentó con la venta de literatura cristiana hasta que la Misión en Estados Unidos acordara remunerarles (Diener, 1947).

El establecimiento de esta Misión en el sur chileno respondió a la información que recibieron los misioneros en el viaje de ingreso al país, en el cual se encontraron con Williams Bishop Boomer, un ministro que se encontraba en Chile colaborando con la Iglesia Presbiteriana desde 1887. Éste les informó acerca del panorama religioso en el cual se encontraba el país insinuándoles que el mejor campo para ellos sería el sur de Chile, porque no había ninguna organización misionera establecida en esta parte; y también porque habían muchos alemanes a quienes podían ayudar, particularmente porque Weiss dominaba el idioma (Oyarzún,1921; Anderson,1990). Aparentemente, Boomer desconocía que en el territorio de La Frontera se encontraba establecida la Misión Anglicana (South American Missionary Society) que había iniciado su culto en 1861 en la ciudad de Lota, actual Región del Bío Bío y avanzó hasta la zona de la tradicional Frontera entre 1893 y 1890 (Zabala, 2008), colaborando en el proceso militar llamado "Pacificación de la Araucanía", una política del Estado chileno para incorporar a La Frontera al territorio nacional, principalmente por asuntos económicos (Pinto, 2011), desconocía además que ya se habían establecido comunidades luteranas en Osorno y Puerto Montt en 1863 y en Valdivia en $1885^{7}$. Sin embargo el imaginario religioso ya se encontraba modelado producto de la instalación de diversas congregaciones católicas que dominaron el discurso cristiano de todo el territorio nacional incluyendo las zonas menos modernizadas, como lo fue desde La Frontera hacia el sur.

Albert Dawson se incorporó rápidamente a la cotidianeidad de la población sureña. Sin embargo, no pasó mucho tiempo en manifestar su preocupación a la Misión en Estados Unidos afirmando que 'tengo dinero y puedo mantenerme a mí mismo. Pero necesito un ayudante nacional porque se hace imposible seguir trabajando sin uno de ellos. El gasto por este ayudante será de $\$ 100$ en oro por un año. El trabajo es brillante y alentador'?

\footnotetext{
${ }^{6}$ Revista The Alliance, 14 de mayo de 1897, página 468. Traducción del autor.

${ }^{7}$ Sin embargo, estas comunidades no tenían el carácter de "misioneras" sino que su actividad se reducía al culto, celebrado en el idioma del país de origen y a la asistencia pastoral de sus respectivas comunidades étnicas (Salinas, 1987, p. 250).

${ }^{8}$ Revista The Alliance, 23 de marzo de 1898, página 283. De acuerdo a los reportes enviados por el misionero Emilio Olssen, superintendente de la Misión para América del Sur, la petición de Dawson fue aceptada incorporando un ayudante para el mes de Abril de 1898, número que aumentó a 9 ayudantes para el mes de mayo. Esta información fue publicada el 6 de abril y el 11 de mayo en la revista corporativa en Estados Unidos. Traducción del autor.
} 
El apoyo que buscaba lo encontró en los colonos alemanes y suizos radicados en las localidades de Quillem y Contulmo, los que en esa época no se habían organizado en sus respectivos cultos, sino que lo hicieron posteriormente en torno al trabajo misional de los misioneros norteamericanos. Los primeros esfuerzos de la Misión The Alliance no radicaron en la adhesión de población chilena ni originaria sino en la organización de la población colona de la zona norte de La Frontera, hecho que se evidenció con la fundación de su primera capilla en la ciudad de Victoria, en 1899 (Woerner, 1997), donde predominó el componente germano en la celebración de los primeros servicios religiosos, aspecto que fue progresivamente transformándose hacia los intereses de evangelizar a la población nacional.

Un año antes, en Abril de 1898, Albert Dawson reportó su primer viaje apostólico traspasando al sur de La Frontera ${ }^{9}$ llegando hasta la Isla de Chiloé, hecho que puedo considerarse un hito para la época porque ninguna organización misionera había penetrado al sur del río Cautín para hacer una abierta propaganda de un culto no católico y establecer una estación o una capilla.

La legislación chilena impedía el ejercicio libre de otro tipo de creencias y las Misiones no católicas eran aún débiles en el territorio nacional (Becerra, 2013). Finalmente Dawson se radicó en Valdivia y abrió una sala de predicación durante 1899, año en que también inició la construcción de la primera capilla de la The Alliance para creyentes nacionales de habla castellana, reportando a Estados Unidos que '...En Chile tenemos dos estaciones y cuatro misioneros. El Sr. y la Sra. Weiss en Victoria y los Sres. Dawson y Rose en Valdovera (sic) [por querer decir Valdivia]. Ahí han habido muchos bautismos y evidencias que animan el trabajo durante la guerra'. 10

\footnotetext{
${ }^{9}$ Revista The Alliance, 10 de agosto de 1898, página 139. Según su propio testimonio, Dawson viajó a Valdivia junto al matrimonio Weiss y una colaboradora de la colonia alemana el 23 de abril de 1898 . En ese viaje casi muere ahogada una de las mujeres al momento de cruzar un río con fuerte caudal. Dawson perdió la literatura y la propaganda que llevaba para anunciar su culto en Valdivia. Pernoctaron en una choza de paja, donde el fuego se encontraba en el centro de la habitación.

${ }_{10}$ Revista The Alliance, 5 de enero de 1899, página 178. Peter Rose fue un misionero noruego que llegó a Chile junto a su esposa y se asoció solo por un tiempo a Dawson y luego se trasladó a San Fernando y se asoció a la Misión Presbiteriana. No se han encontrado más antecedentes de este personaje.
} 


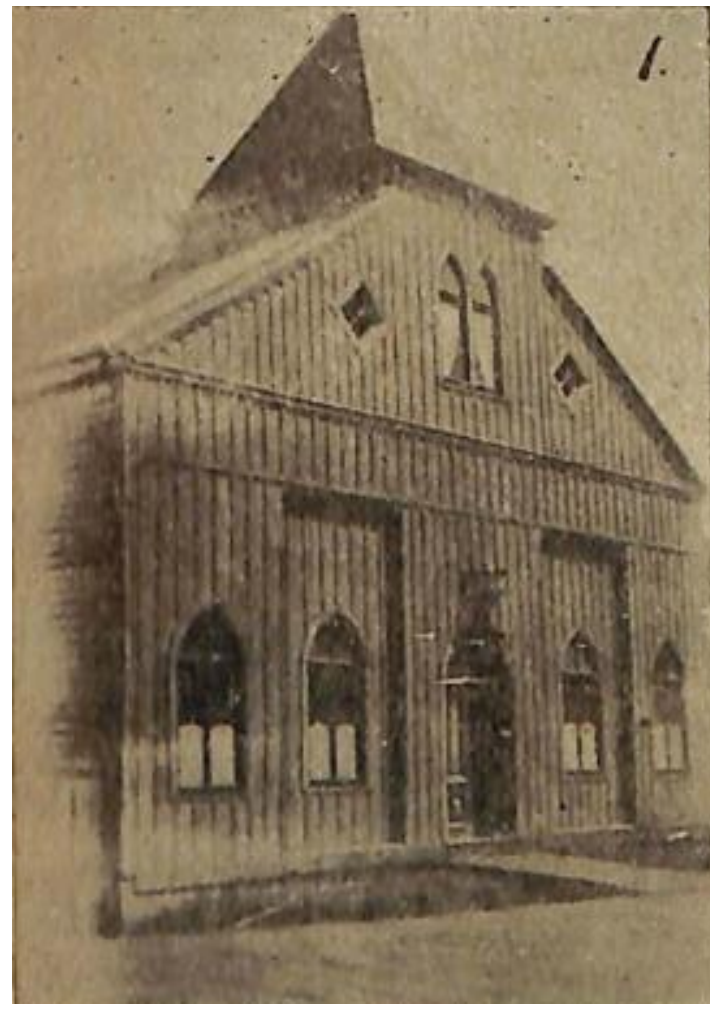

Figura 2. Fotografía de la capilla de la Misión The Alliance que albergó a la comunidad religiosa fundada por Dawson en 1899. La capilla fue inaugurada a fines de octubre de 1900 (posiblemente el día 24).

Weiss se dedicó a trabajar junto a los colonos de Victoria y sus alrededores mientras que Dawson hizo la primera avanzada hacia el sur de La Frontera. El escenario religioso de Valdivia se encontraba tensionado por el reciente establecimiento del culto luterano en 1885 . El proceso de integración de la Misión The Alliance en el imaginario religioso se vio enfrentado a una serie de manifestaciones de repudio por parte del componente católico y luterano. Dawson evangelizó en la ciudad junto a un ayudante chileno (Wenceslao Valdivia), acto que significó la conversión de las primeras seis personas chilenas y dos familias alemanas, los Preisler y Petersen; Sin embargo los misioneros "chocaron entre el propio elemento protestante con tal indiferencia y aun enemistad abierta, que resultaba peor que las persecuciones de los chilenos católicos" (Woerner, 1997, p. 24). La fundación de la comunidad religiosa de Valdivia es atribuida a la acción apostólica de Dawson y de su ayudante.

El proceso de sacralización de un espacio privado para la Misión The Alliance en Valdivia fue costoso porque las persecuciones contra los misioneros se produjeron en el plano de la materialidad y de las ideas religiosas. La lucha por establecer un lugar de culto resultó en una constante itinerancia porque debían arrendar una sala o una casa para celebrar sus liturgias. La reputación esta Misión fue afectada por las insistentes condenas que venían de la curia católica valdiviana: 
...Se les decía que su religión no tenía templos, altares, ni púlpitos, que en cualquier pieza se ponían a adorar a Dios y por tanto, tal adoración no era a Dios, sino al diablo [...] El día de la inauguración del templo de Valdivia fue apedreado por opositores, quebrando todos los vidrios del templo. La solución fue reemplazar los vidrios por malla de gallina... una medida no muy estética pero segura". (Woerner, 1997, p. 3637).

El templo significó una marca de sacralización que le revindicó frente a la población local, validándolo como un culto cristiano y no pagano. La lucha por la permanencia de la prédica protestante en Valdivia se desarrolló en una serie de debates de desprestigios. A la llegada de Henry Weiss, pues abandonó Victoria cuando estuvo consolidado el culto entre los germanos habiendo dejado como obrero religioso posiblemente al colono August Berg ${ }^{11}$, comenzó su trabajo de imprenta con el objeto de producir propaganda para contra argumentar y defender la prédica de la mala reputación originada desde la curia católica. Caso emblemático resultó una publicación del periódico bisemanal llamado El Mensajero ${ }^{12}$ el cual trató explícitamente a los misioneros de la The Alliance como "advenedizos protestantes masones condenados, que han llegado a intranquilizar e infectar las conciencias y almas pacíficas e inocentes de los fieles católicos" (Diener, 1947, p. 30) denominándolos además como coludos y mano negra, apodos que luego se generalizaron para todos los cultos no católicos en el sur chileno durante ese período. Fue así que surgió el primer periódico de la Misión norteamericana en el país, llamado La Alianza Cristiana, que luego cambió su nombre a La Esperanza y a La Verdad, nombre que duró hasta 1912. Esto se debió a que los sacerdotes Antonio María Vío, de Valdivia y Bereaud de La Unión interpusieron querellas judiciales porque el trabajo de la Misión The Alliance se encontraba fuera del marco de la ley por hacer propaganda a un culto no católico (Woerner, 1997, p. 31). Las tenciones derivadas de los propios desprestigios escritos entre los cultos posicionó a Henry Weiss como un precursor del pensamiento liberal porque además de difundir la nueva doctrina, debatió públicamente por los derechos de libertad de prensa y de pensamiento (Fletcher \& Ropero, 2008, p. 391), siendo posicionado por la curia católica valdiviana en el grupo de los masones porque sus ideas liberales coincidían con la propuesta de esta logia ${ }^{13}$. Los misioneros de la The Alliance fueron vinculados al liberalismo y su artificial asociación con la logia masona lo puso en el marco de la sospecha tensionando aún más su trabajo apostólico entre la población valdiviana. Su estrategia de prensa defensiva cuasi

\footnotetext{
${ }^{11}$ Se presume que fue el colono August Berg porque éste fue quien apoyó directamente a los misioneros de la The Alliance para que celebren los cultos protestantes facilitando su hogar para este efecto (Diener, 1947, p. 18), aunque el nombre del colono Otto Berg Schablowsky también es presumible porque su nombre aparece dentro de los obreros oficiales asociados a esta Misión en el listado de la revista de The Alliance del 24 de Septiembre de 1904, página 271.

12 Este periódico es uno de los tantos ejemplares que surgieron a fines del siglo XIX y a inicios del XX para fortalecer las creencias católicas y combatir las sectas protestantes. Ver: Loyola Tapia, Manuel. "EI apostolado de la prensa. La actuación del salesiano Bernardo Gentilini”, en Universum 27 (1), 2012, 85 109. Editorial Universidad de Talca. Chile.

${ }^{13}$ Caso similar al del misionero David Trumbull, presbiteriano, el cual sí fue parte de la Logia Masónica de Santiago (Castro, 2013). Aparentemente todo personero que representaba un culto no católico era catalogado como "masón" sólo por las ideas teológicas libertarias que, al fin y al cabo, eran muy similares a las ideas del liberalismo y laicismo surtidos desde el inicio de la República y potenciados por el ingreso de migrantes al país.
} 
apologética y la propaganda de la nueva propuesta religiosa curiosamente les favoreció porque "de parte del pueblo común la misma lucha despertó un vivo interés por todo nuestro material de lectura" (Diener, 1947, p. 31).

Mientras Weiss defendía su prédica en Valdivia, Albert Dawson tomó un rol más activo en lo misional visitando los pueblos de Río Bueno, La Unión y Osorno y pese a la mala propaganda que había levantado la curia católica y las sospechas de la población, el desarrollo del nuevo culto con la adhesión de población colonizadora y nacional arrojó para el año 1900 resultados que los mismos misioneros reportaron de este modo:

En la República de Chile la Alianza tiene cinco misioneros, el [matrimonio] Weiss, el Sr. Dawson y el [matrimonio] Rose. Los Rose se asociaron al trabajo durante el año pasado. Tres provincias están ocupadas... Chiloé, Voliva y Osoren (sic) [por decir "Valdivia y Osorno"]. Hay catorce lugares de culto, un número total de miembros de 238, y con sesenta personas convertidas que esperan ser bautizadas. Treinta y cuatro [personas] fueron bautizadas el año pasado. Gran parte del trabajo se realiza entre las tribus indias [mapuches], que están en estrecho contacto con esta Misión. Hay un gran trabajo editorial que lleva a cabo un cristiano nativo, con una impresora [que edita] grandes cantidades de literatura cristiana para distribuirla, incluyendo muchas traducciones de los libros y folletos de The Alliance. La Misión informa $\$ 920.76$ reunidos. Dos importantes reuniones fueron realizadas durante el año, una para los nativos de Quillem, que duró tres días [...] La otra fue para los miembros alemanes...que forman un gran asentamiento en este territorio. Un gran espíritu misionero se manifestó entre los acuerdos y se hicieron muchas promesas, incluso de los más pobres, para difundir el evangelio. El trabajo no ha estado exento de [dificultades] y tres de los hermanos nativos fueron encerrados en la cárcel pública durante el año por la predicación del evangelio ${ }^{14}$.

El rápido avance de la Misión The Alliance en el territorio sur chileno puso en evidencia su carencia organizacional pues, en esencia era una organización protestante que enviaba misioneros y misioneras y no una iglesia histórica establecida, como era el caso de la Iglesia Presbiteriana, Luterana o Metodista, incluso se pueden también considerar las órdenes

${ }^{14}$ Revista The Alliance, 19 de mayo de 1900, página 325. 
católicas, las cuales gozaban de una tradición en su organización eclesial, sus declaraciones de fe y sus doctrinas que modelaban sus prácticas cultuales.

Al respecto, la Misión The Alliance tenía la imperante necesidad de modelar una identidad eclesial surgida desde los propios cultos de origen de Albert Dawson (metodista) y el Matrimonio Weiss (menonitas) y no menos importante de los primeros adheridos colonos europeos de tradiciones bautistas, luteranos y calvinistas. Para subsanar esta carencia, el 04 de marzo 1901 los misioneros celebraron su primera conferencia anual en Valdivia, la cual arrojó la primera constitución de la Misión en Chile. Ésta consistió en la elaboración de una declaración de fe y estableció las prácticas doctrinales a las cuales debían anclarse las actividades religiosas, devociones, ritos y enseñanzas (Woerner, 1997, p. 35).

En 1902 Albert Dawson colaboró en la construcción de la capilla de la Misión The Alliance en el poblado de Pitrufquén afirmando que:

Con alegría puedo anunciar que construimos una pequeña capilla en Pitrufquén, capaz de albergar entre 150 a 175 personas. Fue inaugurado el 13 de abril, gran parte del trabajo fue realizado por mis propias manos ${ }^{15}$.

Ese mismo año retornó a Norteamérica y regresó desposado a fines de 1903 estableciéndose en La Unión, donde compró un terreno cerca de la plaza principal y construyó una capilla y su residencia. Esta capilla significó la primera marca material de un culto no católico en la ciudad, fue fundada en $1904^{16}$ y fue destruida por un incendio en Enero 1913 (Leal, 1971, p. 51; Woerner, 1997, p. 39), finalmente fue reconstruida en 1917. Durante 1905, Dawson y su esposa se enfermaron de viruela, epidemia que afectó a gran parte del sur chileno durante esos años. Su primer hijo también se enfermó y falleción ${ }^{17}$. El sufrimiento personal de Dawson sumó a los abusos de la curia católica, representada por el sacerdote Bereaud, el cual ... No desperdiciaba oportunidad de hacernos sentir y pagar caro donde y como quiera que hallaban ocasión propicia”... (Diener 1947, p. 30-32). Su actividad apostólica la extendió hacia Río Bueno logrando en poco tiempo establecer la Misión en el pueblo..." Estamos pensando construir una capilla este año, ya que la habitación que tenemos ahora es demasiado pequeña para acomodar a toda la gente". ${ }^{18}$

\footnotetext{
15 Revista The Alliance, № 8, Vol. XXIX, 23 de agosto de 1902, 100.

${ }^{16}$ Durante el año 1904 Dawson reportó a Estados Unidos que en La Unión celebraban cuatro reuniones semanales y sus visitas a la hermandad eran reiteradas. Visitó Valdivia cuatro veces, Osorno cinco veces y viajaba una vez a la semana a Río Bueno. Durante ese año la Misión se cerró dos meses producto de la viruela. Este testimonio es parte de un reporte informado por Henry Weiss en la Conferencia Anual de la The Christian \& Missionary Alliance, en Estados Unidos.

${ }_{17}$ El hijo del matrimonio Dawson finalmente fue sepultado en el Cementerio Alemán de Valdivia el 06 de Diciembre de 1905. Posteriormente el matrimonio de misioneros tuvo dos hijos.

${ }^{18}$ Revista The Alliance, 3 de abril de 1905, página 136.
} 


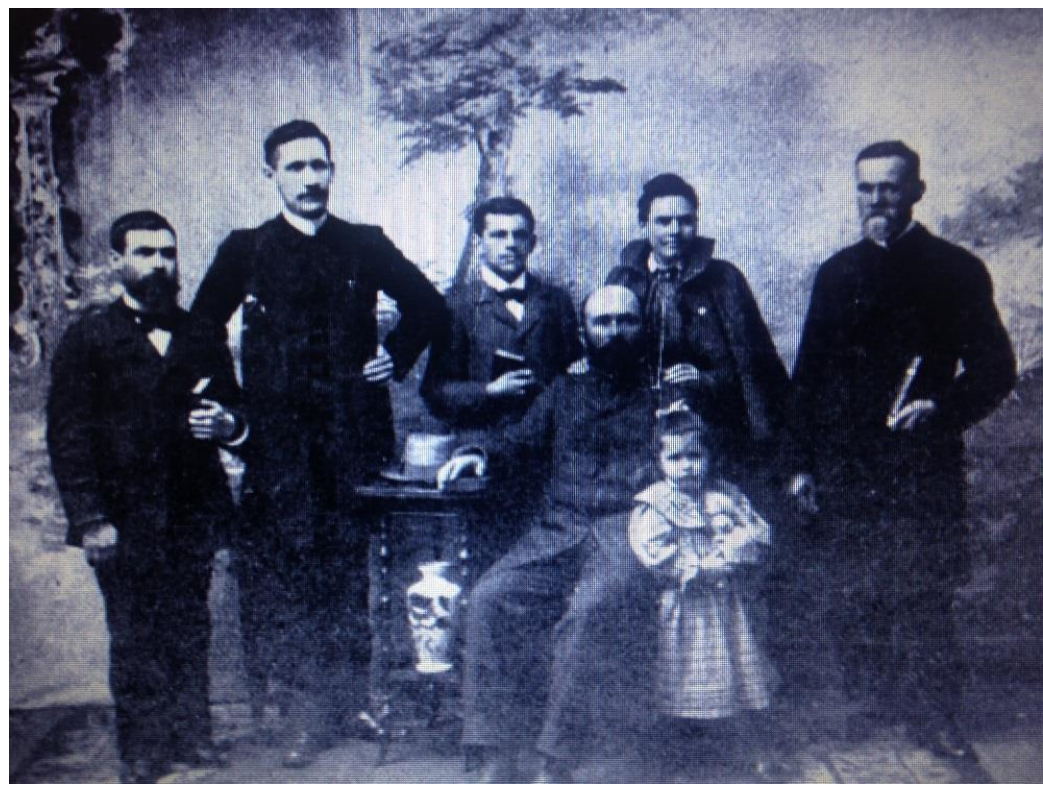

Figura 3. Fotografía de los misioneros de la Misión The Alliance y sus colaboradores en 1901. (De izquierda a derecha) David Mansilla, Albert E. Dawson, Wilfred Diener, Henry Weiss, Katherine Zacharias, Marie (hija del matrimonio Weiss), Williams MacDonald.

Luego de cumplir su objetivo en La Unión, Dawson se trasladó en 1907 a Loncoche. Sus actividades misionales las realizó entre la población chilena y mapuche porque la presencia de población colona no era tan importante en la zona. El misionero se dedicó en gran medida a entender e integrarse a la cultura mapuche. La Misión carecía de pertenencias étnicas y socio económicas, pues su objetivo fue exclusivamente religioso y se adaptaba a cada grupo de población a la cual se dirigía. De hecho, desde su llegada al territorio del sur chileno, los misioneros se vincularon rápidamente con los indígenas, aun cuando su trabajo apostólico no fue inicialmente dirigido a ellos. Los testimonios analizados dan cuenta de diversas marcas de penetración en la población mapuche:

...Los indígenas de Chile poseen y cultivan sus propias granjas; muchos de ellos hablan el idioma español y están adoptando gradualmente la vestimenta más parecida posible. No son nómadas, como las tribus de la Montaña, sino que viven en antiguas casas en mal estado construidas de troncos colocados en el extremo, unidos entre sí y tienen un techo de hierba nativa o paja; [no tienen piso] sino arcilla endurecida; sólo hay una habitación y el fuego se construye en el centro de ésta, el humo escapa a través de la puerta o un agujero en el techo. La crianza de ganado es 
su principal [producción]; las mujeres tejen telares. [Adoran] a un espíritu bueno y otro mal. Su creencia es una extraña mezcla de paganismo y se asemeja a las antiguas costumbres judías. Por lo general son hospitalarios, amables y abiertos al evangelio, y son muy superiores a los indios de América del Norte"...19

La estrecha relación que tuvo el misionero con el pueblo mapuche se evidencia en la serie de marcas materiales e imaginadas entre las diversas comunidades indígenas donde desarrolló sus actividades apostólicas, manifestando desde su experiencia y testimonios que los indígenas chilenos eran pacíficos y respondían a su llamado evangelizador, adoptando nuevas concepciones y prácticas religiosas, sacándolos de sus creencias originarias vistas por él como paganas y posicionándolos en el lugar de claridad que les proveía la propia Misión, instalando así su culto en medio de ellos como un dispositivo de dominación. Este caso representa el sentido de superioridad que Dawson otorgaba a su culto frente a las creencias mapuches, caso que bien puede reflejar la diferenciación de civilización y barbarie que teoriza Walter Mignolo (2007).

Para 1908 Dawson reportó la apertura de un nuevo lugar de culto, en La Paz, una villa formada en torno a una estación de trenes al norte de Loncoche. Para el año 1909 inició una escuela en Loncoche, alcanzando una matrícula de 40 estudiantes. Por su condición ilustrada y profesional extranjero, las actividades educativas gozaron de cierto prestigio entre la población local, permitiendo alfabetizar a los niños y enseñarles la doctrina cristiana. La escuela "también ha abierto las puertas de muchos hogares para celebrar reuniones" (Woerner, 1997, p. 291).

Este es el último reporte de actividades del misionero en el territorio nacional. Esto no significó que haya abandonado su función, sino que siguió fortaleciendo las estaciones de la Misión, mientras predicaba en otros espacios donde él observaba la necesidad de instalar capillas. El año 1914 se fue del país para radicarse en Norteamérica. No hay reportes que den cuenta de su trabajo religioso, el que posiblemente lo realizó en calidad de pastor y no de misionero. Sin embargo, sus vínculos con la Misión The Alliance no desaparecieron, de hecho se encuentra firmando como comisionado de esta Misión en una de las mesas formadas en el Congreso de Panamá del año 1916, pero residiendo en la localidad de Oxbox, en la provincia de Saskatchewan en Canadá (The Missionary Education Movement, 1917, p. 200).

Otros testimonios de Albert Dawson analizados, dan cuenta del activo protagonismo que adoptó contra la curia católica establecida en el territorio donde desarrolló sus actividades misionales. Reiteradamente se presentó como un detractor del poder hegemónico del cual gozaba la Iglesia Católica y las posicionaba en el plano de lo sincrético y pagano y no de lo sacro. Su pública crítica anticatolica la evidenció rápidamente cuando en 1901 elaboró un manual de pruebas para contradecir las falsas doctrinas de la Iglesia Católica Romana (Woerner, 1997, p. 29). Por tanto, la población católica se volvió un objetivo para el culto aliancista. A modo de ejemplo, precisamos uno de sus testimonios:

...El misionero Albert Dawson regresó de Sudamérica, y entregó una imagen muy gráfica de la adoración idolátrica de los católicos en ese país sumergido en la

${ }^{19}$ Revista The Alliance, 22 de Julio 1911, página 268. 
ignorancia. Leyó el décimo capítulo de Romanos, y comparó a los romanistas de América del Sur como a los que Pablo les estaba escribiendo [...] nada es muy difícil para ellos, si lo hacen en el nombre de algún santo o de la propia Iglesia. Tienen numerosas procesiones durante el año, y una descripción de una de ella es copia razonable de las demás. Imagínese una multitud de diez a veinte mil [personas] luchando como demonios para obtener la mirada de un sacerdote o un obispo, o besar su ropa. Ellos marchan a través de la ciudad hasta la plaza donde a cada lado hay un altar, donde hay veneraciones. En la procesión hay cualquier número de santos en madera etc. Tales como San Antonio, Francisco, Juan, Pedro, Pablo, etc...."20

Para Dawson, las prácticas religiosas católicas eran la representación de la idolatría y la ignorancia, otorgándole a su propio discurso religioso (metodista en esencia) un sentido de superioridad frente al culto establecido. Sus públicas condenas tensionaron el imaginario religioso establecido, hizo enojar a la curia católica, dando origen a una serie de episodios de abiertos debates teológicos que finalmente dieron por consecuencia su propia persecución. El "romanismo", así llamó a todo lo que denotaba ser católico, lo consideraba como una religión sumergida en las tinieblas, desconociendo las diversas advocaciones a los santos como devociones cristianas porque respondían a la paganidad que él mismo condenaba. En consecuencia, Dawson y la Misión The Alliance fueron abiertos "enemigos" del catolicismo porque sus discursos iban en desestructurar tanto su dogmática como su forma de gobierno.

\section{Comentarios finales}

A partir de la segunda mitad del siglo XIX el territorio sur chileno inició un proceso de incorporación de nuevos cultos de corrientes reformadas. Evidencia de ello es lo que, anclado al misionero Albert Dawson, pretende dar a conocer el presente artículo. Las tenciones religiosas surgidas desde la Misión The Alliance dan cuenta de las diversas reacciones de repudio de la curia católica, quienes mantuvieron la hegemonía del imaginario religioso chileno desde épocas coloniales. El cambio poblacional, con el ingreso de migrantes europeos de diversas procedencias religiosas reformadas favoreció el establecimiento de los cultos no católicos, aspecto que dio más fuerza al proceso de secularización que comenzó a enfrentar el Estado chileno.

Con la modificación del imaginario religioso en el sur chileno, se inició una resignificación del discurso cristiano. La Iglesia Católica ya no era la única que proveía de verdad y luz a la población, sino que los nuevos cultos también lo comenzaron a hacer mediante sus propias concepciones teológicas y prácticas rituales.

\footnotetext{
${ }^{20}$ Revista The Alliance, 21 de junio 1902, sin página.
} 
El rol de la Misión The Alliance contra la curia romana evidenció, en la persona del misionero Albert Dawson, la capacidad martirológica que adoptó esta organización para llevar a cabo su acción apostólica en la búsqueda de adhesión de poblaciones locales. El sentido de lo sagrado también causó modificaciones en la materialidad, la construcción de capillas, como símbolos sagrados de los cultos no católicos fracturó el sentido sacro que sólo gozaban los símbolos católicos (templos, capillas, misiones, grutas, etc.). La Misión The Alliance tomó un rol condenatorio frente a las prácticas rituales de los católicos, entendiéndolas como alejadas de las ideas bíblicas de devoción, por lo tanto, respondían a conductas de paganidad más que a conductas de devoción cristiana. De aquí surgieron las principales manifestaciones de repudio y atentados contra los misioneros.

\section{Referencias}

Almonacid Zapata, F. (2009). El problema de la propiedad de la tierra en el sur de Chile (1850 1930. Historia, 1 (42), 5-56.

Anderson, J. (1990). Historia de los bautistas. Texas: Casa Bautista de Publicaciones.

Becerra, R. (2013). Amando al prójimo a la luz del Evangelio. Osorno: Sociedad Periodística Araucanía.

Carvajal, P. (2009). La doctrina católico-española del siglo XVII sobre el Estado. Monarquía, Estado e Imperio. Revista de Estudios Histórico - Jurídicos, XXXI, 371-397.

Castro, J. (2013). David Trumbull, entre masonería y protestantismo: la conformación del frente anticlerical en Chile a fines del siglo XIX. Religiao e Sociedade. 33 (1), 98-121. Recuperado de http://www.scielo.br/scielo.php?script=sci_arttext\&pid=S010085872013000100006

Diener, W (1947). Medio siglo de testimonio para Cristo. Temuco: Editorial Alianza.

Dobbelaere, K. (1994). Secularization: a multi-dimensional concept. Londres: SAGE publications.

Fletcher, J.; Ropero, A. (2008). Historia general del cristianismo. Del siglo I al siglo XXI. Barcelona: Editorial CLIE.

García Leguizamón, F. (2012). Protestantes, evangélicos y pentecostales: aclaraciones conceptuales preliminares en un campo de investigación social. Revista Folios. (36) 171 - 187. Recuperado de: http://www.scielo.org.co/pdf/folios/n36/n36a10.pdf

Izquierdo, A. (2003). La filosofía en contra de la religión. Santiago de Chile: Edaf ensayos.

Larraín, J. (2003). Dios desde una mirada sociológica. En: Santibáñez, Hopenhayn, Rivera, Feldmann, y otros. Dios en el mundo de hoy. Santiago de Chile: Ediciones Universidad Diego Portales.

Leal, O. (1971). Historia de la ciudad de La Unión en sus 150 aniversarios. 1821-1971. Santiago de Chile: s.d.e.

Loyola Tapia, M. (2012). El apostolado de la prensa. La actuación del salesiano Bernardo Gentilini. Universum 27 (1), 85-109.

Mignolo, W. (2007). La idea de América Latina. La herida colonial y la opción decolonial. Barcelona: Editorial Gedisa.

Millar, R. (2000). Aspectos de la sociedad porteña. Valparaíso 1830 - 1930. Historia, 33, 297368.

Millard, E. C. y Guinnes, L. (1894). South America. The Neglected Continent. Fleming Revel Company. Nueva York.

Muñoz, J. (2008). Notas sobre la relación entre alcohol y trabajo en la frontera sur de la Araucanía. Segunda mitad del siglo XIX. En Fernández, M.; Godoy, E.; Herrera, P.; Muñoz, J.; Venegas, H.; Yáñez, J., Alcohol y trabajo (pp. 37-62). Osorno: Editorial Universidad de Los Lagos. 
Muñoz, J. (2010). Contaminación de creencias. Trabajadores en tránsito y el mercado laboral urbano de Osorno, Chile (1880 - 1891). Osorno: Editorial Universidad de Los Lagos.

Ospina, A. (2015). Purificando la tierra. Colonizando el espíritu: conflicto armado y religiosidad en la mítica Marquetalia. Anuario de Historia Regional y de Las Fronteras, 2 (20), 101124.

Oyarzún, A. (1921). Reminiscencias de la obra evangélica en Chile. Temuco: Editorial Alianza.

Pinto, J. (2011). Araucanía, siglos XIX y XX. Economía, migraciones y marginalidad. Osorno: Editorial Universidad de Los Lagos.

Salinas, M. (1987). Historia del pueblo de Dios en Chile. Santiago de Chile: Ediciones Rehue.

Sánchez, M. (2017). Historia de la Iglesia en Chile, Tomo V. Conflictos y esperanzas, remando mar adentro. Santiago de Chile. Editorial Universitaria.

Serrano, S. (2003). Espacio público y espacio religioso en Chile republicano. Teología y Vida $X L I V, 346-355$.

Serrano, S. (2008). ¿Qué hacer con Dios en la República? Política y secularización en Chile (1845 - 1885). Santiago de Chile: FCE.

Shanonn, J. (1997). Una breve historia de la Alianza Cristiana y Misionera en la Argentina. (Documento borrador).

Silveira, A. (2017). Fervor por Dios. Construyendo una identidad común. Las iglesias anglicana y presbiteriana en Buenos Aires (1825 - 1876). Sociedad y Religión, 48 (27), 38-68. Recuperado de: http://www.scielo.org.ar/scielo.php?script=sci_arttext\&pid=S185370812017000200003.

The Missionary Education Movement. (1917). Christian work in Latin America. Survey and occupation, message and method education. Nueva York: Comittee on Cooperation in Latin America.

Zavala, J. (2008). Los colonos y la escuela en la Araucanía: los inmigrantes europeos y el surgimiento de la educación privada laica y protestante en la Región de la Araucanía (1887 - 1915). Universum, 23 (1), 268-286.

Woerner, D. (1997). Desde el siglo y hasta el siglo, Tú eres Dios. Temuco: Editorial Alianza. 
